\title{
Childhood obesity in developing countries
}

\author{
Louis CK Low \\ Hong Kong, China
}

A s far back as 1997, obesity as a public health problem was highlighted in a World Health Organization (WHO) press release which stated that "obesity's impact is so diverse and extreme, that it should now be regarded as one of the greatest neglected health problems of our time with an impact on health which may well prove to be as great as that of smoking". With the exception of Russia, Poland and urban populations of a few low income countries, there has been a steady increase in the prevalence of overweight and obese children and adolescents in developing and developed countries in the past three decades. ${ }^{[1]}$ By $2010,40 \%$ of children in North America, $38 \%$ in Europe, $27 \%$ in the Western Pacific and 22\% in Southeast Asia have been predicted to be overweight or obese. ${ }^{[2]}$ China, India, Pakistan and Indonesia are populous nations with large pediatric populations, undergoing rapid economic development. WHO estimated that $75 \%$ of the 43 million overweight and obese children under 5 years of age worldwide will come from low and middle income countries by the end of this decade. ${ }^{[3]}$ In lower and middle income countries, a double burden of both obesity and undernutrition frequently exists. ${ }^{[1]}$ This is highlighted in the articles by Senbanjo et al ${ }^{[4]}$ and Ziaoddini et al. ${ }^{[5]}$ Obesity rates in developing countries appear to be linked to socioeconomic development, ethnicity, the population working, living and school environment, diet and activity patterns. In a developing country like China, the prevalence of overweight and obesity can vary from $17 \%$ and $10 \%$ in boys in Beijing to $4.9 \%$ and $1.4 \%$ of children in inland rural cities. ${ }^{[6]}$

The increasing prevalence of overweight and obesity in children and adolescents is a public health concern because of the association with adult obesity and increased

Author Affiliations: Department of Paediatrics and Adolescent Medicine, The University of Hong Kong, China (Low LCK)

Corresponding Author: Louis CK Low, MBChB, FRCPCH, FHKAM (Paed), Queen Mary Hospital, Pokfulam Road, Hong Kong SAR, China (Tel: (852) 2255-4090; Fax: (852) 2855-1523; Email: lcklow@hkucc.hku. hk)

doi:10.1007/s12519-010-0217-9

CChildren's Hospital, Zhejiang University School of Medicine, China and Springer-Verlag Berlin Heidelberg 2010. All rights reserved. risk of cardiac events in adulthood. ${ }^{[2,3,7]}$ Every organ system can be affected by childhood obesity and comorbidities include hypertension, non-alcoholic liver disease, insulin resistance, dyslipidemia, pulmonary disorders and psychological problems. ${ }^{[2,7]}$ The clinical approach of identifying children at risk and treating them should be complemented by a public health approach of preventing unhealthy weight gain in the population. In the definition of overweight and obesity, some developed countries use their own national body mass index (BMI) standard. The WHO has adopted the updated BMI reference based on the modified United States NHANES I data collected in 1971-1974 (available at http://www.cdc.gov/growthcharts) while other countries use the BMI cutoff ranges for overweight and obesity with age based on the International Obesity Task Force (IOTF) international growth reference constructed from six representative population growth studies (Brazil, Great Britain, Netherlands, Singapore, Hong Kong and United States). ${ }^{[8]}$ The Scientific Advisory Committee on Nutrition in the United Kingdom recommends using the 2006 WHO Child Growth Standard between 2 weeks and 2 years and to use the 1990 UK Growth reference for older children. The United States recommends the use of Center for Disease Control (CDC) derived normative percentiles ( 85 th-94th percentile as overweight, and $>95$ th percentile as obese). The experts in China recommended the use of the 2005 Working Group on Obesity in China (WGOC) BMI Reference for screening for overweight and obesity in Chinese children. ${ }^{[6]}$ In recent years, waist circumference $>90$ th percentile of the age, sex and ethnic specific reference has been advocated for defining central obesity. ${ }^{[9]}$ For developing countries, each country should evaluate carefully to acertain the most appropriate growth reference for use in the assessment of growth disorders in their population. A recent study found that the difference in the prevalence of overweight in Asian children using the CDC and IOTF cutoffs was small $(<2 \%-5 \%)$, which was similar to the findings from studies on some high-income countries. ${ }^{[10]}$

Although currently there is not enough evidence to recommend screening children for obesity, there are national surveillance programs being implemented to identify children at risk. The key ingredients to achieve 
implementation of population-based childhood obesity intervention include political leadership, policy support, adequate funding for intervention programs and social marketing, monitoring, program evaluation, research and a strategy for integrating scientific evidence into the development of multilevel program. ${ }^{[3,11]}$ With true political leadership, policies have been developed to address the problem of childhood obesity. The Arkansas Child and Adolescent Obesity Initiative includes legislation to mandate annual BMI check for children with the information conveyed to the parents. ${ }^{[1]} \mathrm{A}$ similar surveillance system has been legislated in United Kingdom from 2008 to 2009. Another example is the Trim and Fit Program initiated by the Singapore Government which integrates nutrition education into the school curriculum, promotes physical education and controls the availability of undesirable food and beverages in schools. Parents and children are also educated on healthy eating and physical activity and there are clinics for children identified to be obese. Quebec, Scandinavia and United Kingdom have regulations in place to limit exposure of children to food marketing broadcasted on television or radio. Health promotion programs need to be supported by legislation and enforcement. ${ }^{[3,11]}$

Children spend a significant amount of their day in school and it is logical to initiate programs to promote healthy eating and increased physical activity in school to prevent childhood obesity. However, a Cochrane review showed that school-based interventions focusing on dietary change and physical activity did not significantly improve BMI. ${ }^{[12]}$ A recent meta-analysis reported that the odds of participants being overweight or obese in school-based programs as compared to controls, were significantly protective with longer programs being more effective. ${ }^{[13]}$ Another critical period of intervention will be infancy and early childhood when children are learning about food and eating. Parenting practices shape a child's early experience with food and eating. Appropriate intake of healthy foods can be "learned" by young children if eating such foods is modeled by their parents or is paired with positive and pleasant social context. Much work still needs to be done on interventions in early childhood to prevent obesity. ${ }^{[14]}$ The community capacity building approach has been initiated in Australia and New Zealand which brings the support systems to help the community organizations to build up their own capacity to promote healthy eating and increase physical activity. ${ }^{[15]}$ The successful French EPODE Program involves communities in health education, nutrition and physical activities among 5-12 year old children and their families since 2004. ${ }^{[16]}$ The program will be evaluated and rolled out to other
European countries.

Systematic reviews have been used to synthesize research evidence on obesity prevention with an aim to guide clinical practice and the development of public health intervention policy. Unfortunately, existing metaanalyses of childhood obesity prevention initiatives in early childhood, school-based and community-based programs provide limited practice-relevant information like content, setting, personnel, modalities, intensities, and adverse effects of the interventions. Costeffectiveness of interventions has not received much emphasis but cost information is frequently requested by health decision makers. Better designed studies and meta-analyses are required to identify practice relevant gaps in the literature and to address the limitations of published meta-analyses. Involving end users in the development of high quality systematic reviews has also been advocated.

\author{
Funding: None \\ Ethical approval: Not needed. \\ Competing interest: None. \\ Contributors: Low LCK is the single author of the paper.
}

\section{References}

1 Wang YF, Lobstein, T. Worldwide trends in childhood overweight and obesity. Int J Pediatr Obes 2006;1:11-25.

2 Han JC, Lawlor DA, Kimm SY. Childhood obesity. Lancet 2010;375:1737-1748.

3 World Health Organization. Population-based prevention strategies for childhood obesity. Report of the WHO Forum and Technical Meeting (Geneva, 15-17 December 2009).

4 Senbanjo IO, Oshikoya KA. Physical activity and body mass index of school children and adolescents in Abeokuta, Southwest Nigeria. World J Pediatr 2010;6:217-222.

5 Ziaoddini H, Kelishadi R, Kamsari F, Mirmoghtadaee P, Poursafa P. First nationwide survey of prevalence of weight disorders in Iranian children at school entry. World J Pediatr 2010;6:223-227.

6 Ji CY; Cooperative Study on Childhood Obesity: Working Group on Obesity in China (WGOC). The prevalence of childhood overweight/obesity and epidemic changes in 19852000 for Chinese school-age children and adolescents. Obes Rev 2008;9 (Suppl 1):78-81.

7 August GP, Caprio S, Fennoy I, Freemark M, Kaufman FR, Lustig RH, et al. Prevention and treatment of pediatric obesity: an endocrine society clinical practice guideline based on expert opinion. J Clin Endocrinol Metab 2008;93:4576-4599.

8 Cole TJ, Bellizzi MC, Flegal KM, Dietz WH. Establishing a standard definition for child overweight and obesity worldwide: international survey. BMJ 2000;320:1240-1243.

9 Sung RY, Yu CC, Choi KC, McManus A, Li AM, Xu SL, et al. Waist circumference and body mass index in Chinese children: cutoff values for predicting cardiovascular risk factors. Int J Obes (Lond) 2007;31:550-558. 
10 Tuan NT, Nicklas TA. Age, sex and ethnic differences in the prevalence of underweight and overweight, defined by using the CDC and IOTF cut points in Asian children. Eur J Clin Nutr 2009;63:1305-1312.

11 Swinburn B. Obesity prevention in children and adolescents. Child Adolesc Psychiatr Clin N Am 2009;18:209-223.

12 Summerbell CD, Waters E, Edmunds LD, Kelly S, Brown T, Campbell KJ. Interventions for preventing obesity in children. Cochrane Database Syst Rev 2005;(3):CD001871.

13 Gonzalez-Suarez C, Worley A, Grimmer-Somers K, Dones V. School-based interventions on childhood obesity: a metaanalysis. Am J Prev Med 2009;37:418-427.
14 Hesketh KD, Campbell KJ. Interventions to prevent obesity in 0-5 year olds: an updated systematic review of the literature. Obesity (Silver Spring) 2010;18 Suppl 1:S27-35.

15 Swinburn B, Pryor J, McCabe M, Carter R, de Courten M, Schaaf D, et al. The Pacific OPIC Project (Obesity Prevention in Communities) - objectives and designs. Pac Health Dialog 2007;14:139-146.

16 EPODE. Ensemble prevenons l'obesite des enfants. www. epode.fr.

Received July 15, 2010

Accepted after revision July 19, 2010 